9. Friedman E. Increased scleral rigidity and age-related macular degeneration / E. Friedman, M. Ivry, E. Bbert et al. // Ophthalmology. - 1989. - 96, N 1. - P. 104-108.

10. Gass JDM. Drusen and disciform macular detachment and degeneration/ JDM Gass// Trans Am Ophthalmol Soc. - 1972. - Vol.70. - P. 409-436.

11. Holz F. G. Pathogenesis of lesions in late age-related macular disease / F. G. Holz, D. Pauleikhoff, R. Klein, et al. // Am J Ophthalmol. - 2004. - Vol. 137. - P. 504510 ,

12. Hoskin A. Tears of detached retinal pigment epithelium / A Hoskin, AC Bird, K Sehmi // Br J Ophthalmol. 1981. - Vol. 65. - P. 417-422.

13. Jager M. J. Macrophages feel their age in macular degeneration [Text] / M. J. Jager, C. C. W. Klaver // The Journal of Clinical Investigation. - 2007. - V.117. - № 11. P. 3182-3184.
14. Moorfields macular study group. Retinal pigment epithelial detachments in the elderly:a controlled trial of argon laser photocoagulation / Moorfields macular study group // Br J Ophthalmology. - 1982. - Vol.66. - P. 1-16.

15. Ruth Axer-Siegel. Photodynamic therapy for occult choroidal neovascularization with pigment epithelium detachment in age-related macular degeneration/ Axer-Siegel Ruth, Ehrlich Rita, Rosenblatt Irit, et all// Arch Ophthalmol. - 2004. - Vol.122. - P.453-459.

16. Smith B. T. Retinal pigment epithelial tears in ranibizumab-treated eyes / B. T. Smith, C. L. Kraus, R. S. Apte // Retina. - 2009. - Vol.29. - Issue 3. - P. 335-9.

17. Verhoeff F. H. Pathogenesis of disciform degeneration of the macula / F. H. Verhoeff, H. P. Grossman // Arch Ophthalmol. - 1937. - Vol.18. - P.561-585.

18. Yong Tao. Intravitreal Triamcinolone / Tao Yong, Jonas Jost B. // Ophthalmologica. - 2011. - Vol.225. - P.1-20.

\title{
EFFICACY OF INTRAVITREAL APPLICATION OF TRIAMCINOLONE ACETONIDE IN TREATMENT OF PATIENTS WITH TRANSSUDATION DETACHMENT OF RETINAL PIGMENT EPITHELIUM IN AGE-RELATED MACULAR DEGENERATION
}

N. V. Pasechnikova, A. R. Korol, O. S. Zadorozhnyy, T. B. Kustrin, A. A. Nevskaya

Intravitreal application of triamcinolone acetonide permits to get decrease of height and extension of transsudation detachment of retinal pigment epithelium (RPE) during 18 months. Retachment of the RPE observed in $32 \%$. Visual acuity remains stable. Tear of RPE and development of subretinal neovascularization were absent.

УДК 617.735-007.281-085:615.21-073.524

\section{ВЛИЯНИЕ КОРТЕКСИНА НА ФОТОПИЧЕСКУЮ СВЕТОВУЮ ЧУВСТВИТЕЛЬНОСТЬ У БОЛЬНЫХ С РЕГМАТОГЕННОЙ ОТСЛОЙКОЙ СЕТЧАТКИ}

\section{В. С. Пономарчук, Н. И. Храменко, Гаффари Сахби Бен Мохамед Монсеф}

\author{
ГУ «Институт глазных болезней и тканевой терапии им. В. П. Филатова НАМН Украины»
}

Ключевые слова: регматогенная отслойка сетчатки, кортексин, фотопическая световая чувствительность

Введение. Известно, что регматогенная отслойка сетчатки (РОС) является тяжелым инвалидизирующим заболеванием органа зрения (9\% случаев утраты трудоспособности и слепоты) [7, 8]. В настоящее время отмечаются значительные успехи в хирургическом лечении данного заболевания: прилегания сетчатки после нескольких вмешательств удается достичь в 92-100\% случаев, однако значимого улучшения функциональных результатов при этом не наблюдается $[7,8,14]$. Причиной неполного восстановления зрительных функций, прежде всего остроты зрения, являются необратимые процессы ишемического характера в сетчатке при ее отслойке, что определяет необходимость разработки эффективных методов лечения и реабилитации больных, а также их социально-экономическую значимость [13, 14, 15].

Возможным путем решения данной задачи является улучшение метаболических процессов в сет- чатке после ее прилегания, что может повысить и/ или ускорить возможное восстановление ее структурных элементов и обеспечить более высокие функциональные результаты лечения.

Предметом выбора стал препарат, являющийся регулятором функций центральной нервной системы (ЦНС) - нейропептид кортексин, который свободно проникает через гематоэнцефалический барьер [2, 3]. Кортексин представляет собой сбалансированный комплекс нейропептидов, $\mathrm{L}$-аминокислот, витаминов и микроэлементов с оптимальным соотношением между возбуждающими (глутаминовая кислота, аспартат, глутамин) и тормозными (глицин, таурин, фрагменты гаммааминомасляной кислоты (ГАМК), серин) аминокислотными нейромедиаторами.

(c) В. С. Пономарчук, Н. И. Храменко, Гаффари Сахби Бен Мохамед Монсеф, 2012 
Препарат обладает ноотропным, нейротрофическим, нейрометаболическим, антиоксидантным, нейромедиаторным свойствами. Кортексин мощный природный антиоксидант, который значительно снижает активность свободнорадикального окисления. Результаты исследований свидетельствуют также о влиянии кортексина на цитокиновый обмен через систему противовоспалительных цитокинов, улучшая нейротрофическое обеспечение нервного волокна, уменьшая аутоиммунную агрессию, способствуя восстановлению и росту аксонов [4]. Таким образом, кортексин воздействует на многие звенья патологической цепи молекулярных событий, приводящих к гибели нейронов.

В офтальмологии известно положительное влияние препарата при дистрофических заболеваниях сетчатки и зрительного нерва [5, 6, 9, 12, 13], рекомендовано также его применение в комплексном лечении и наследственной дистрофии сетчатки (пигментный ретинит, белоточечный ретинит, дистрофия Беста, болезнь Штаргардта, дистрофия желтого пятна) [Організація офтальмологічної допомоги на сучасному етапі, 2008].

Цель работы изучить влияние кортексина на функциональную активность фотопической световой чувствительности у пациентов с РОС

МАТЕРИАЛ И МЕТОДЫ. Ретроспективно изучены результаты успешного лечения 18 пациентов (18 глаз) с РОС (первая группа), которые после операции получали 10 мг кортексина в сутки (внутримышечно ежедневно) на протяжении 10 дней в комплексе с общепринятой терапией после хирургичекого лечения регматогенной отслойки сетчатки. Контрольную (вторую) группу составили 25 человек (25 глаз), получавших только противовоспалительную терапию без кортексина. Возраст больных основной и контрольной групп колебался от 20 до 42 лет. Пациенты с осложнениями хирургического лечения в исследование не включались.

Всем пациентам проводили общепринятое офтальмологическое обследование: визометрию, тонометрию, биомикроскопию, офтальмоскопию, исследование порогов электрической чувствительности и лабильности по фосфену, периметрию.

Для данной работы использована выборка пациентов с максимально сходным исходным клиническим состоянием. Так, характерными для I и II групп были следующие показатели: средняя протяженность отслойки составляла $(7,51 \pm 0,29)$ час и $(7,77 \pm 0,25)$ час; давность отслойки $(27,22 \pm 2,52)$ дней и $(28,64 \pm 2,09)$ дня; давность макулярной отслойки - $(11,6 \pm 1,8)$ и $(13,4 \pm 1,4)$ дней; средняя исходная острота зрения составляла $(0,15 \pm 0,03)$ и $(0,15 \pm 0,23)$, рефракция в послеоперационном периоде в обеих группах была миопической, и в среднем составила $(4,53 \pm 0,1)$ Дптр для первой и $(4,82 \pm 0,6)$ Дптр - для второй с астигматическим компонентом - $(1,22 \pm 0,3)$ Дптр и $-(1,3 \pm 0,4)$ Дптр соответственно. Значения ПЭЧФ не превышали 80 мкА.

У пациентов обеих групп на парном глазу имела место осложненная миопия, в частности, миопическая макулопатия в $19 \%$ и периферическая дегенерация сетчатки различных видов - в $100 \%$ случаев.

Оперативное вмешательство заключалось в проведении эписклерального пломбирования или комплексного интравитреального вмешательства (витрэктомии с газовой тампонадой) по стандартной методике у 8 и10 чел. первой группы и 11 и 14 чел. второй группы соответственно.

Фотопическая световая чувствительность (ФСЧ) световая чувствительность колбочкового фоторецепторного комплекса) определялась на приборе адаптометре регистрирующем полуавтоматическом (АРП) в первом стандартном режиме по заданной программе: 3 минуты - световая адаптация, 7 минут - темновая. Оценка ФСЧ проводилась на основании величины абсолютных световых порогов, определяемых в процессе темновой адаптации на 0, 2, 4, 6 и 7 минутах монокулярно. Яркость стенок шара световой адаптации при ослеплении в течение 3 мин $-1200 \mathrm{Kд} / \mathrm{M}^{2}$, расстояние глаз до испытательного объекта -250 мм. В группу контроля при проведении ФСЧ вошли 5 пациентов (10 глаз) с неосложненной миопией средней степени в возрасте от 19 до 38 лет.

Исследование зрительных функций проводили при плановом осмотре пациентов обеих групп через 5-6 месяцев после проведения операции и последующего медикаментозного лечения.

Статистическая обработка проводилась с использованием Т критерия.

РЕЗУЛЬТАТЫ И ИХ ОБСУЖДЕНИЕ. ПосЛе восстановительного периода (5-6 месяца) в данных выборочных группах больных было полное прилегание сетчатки, отсутствовали осложнения, связанные с проведением хирургической операции, не было грубых изменений в макулярной области, катаракты, повышения ВГД.

Острота зрения с оптимальной коррекцией после лечения была существенно выше исходных: в 1 группе - 0,45 $\pm 0,06$ (колебалась от 0,32 до 0,58), а во второй группе имелась тенденция к более низким

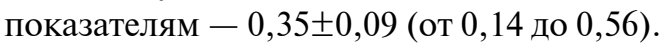

Световая чувствительность глаза - возникновение зрительных ощущений на минимальное световое воздействие (длиной волны электромагнитного излучения от 350 до 750 нм), является основой всех форм зрительного восприятия, имеет интегративный характер, который определяется не только периферическими процессами, происходящими непосредственно в сетчатке, но и уровнем активности нейронных элементов афферентной зрительной системы зрительного анализатора, как и всей ЦНС $[10,11]$.

В I группе пациентов, получавших кортексин, через 5-6 месяцев после окончания медикаментозного лечения, ФСЧ на первой минуте исследования после световой адаптации была равна $(-0,45 \pm 0,08)$ лог. ед., и чуть выше - $(-0,38 \pm 0,09)$ лог. ед. - на парном; во второй группе пациентов (без кортексина) эти значения были ниже $(\mathrm{p}=0,09)$ и составили $(-0,70 \pm 0,07)$ и $(-0,6 \pm 0,10)$ лог. ед. соответственно. На второй минуте исследования ФСЧ имела более высокие значения: 0,06 и 0,01 в I и II группах, однако ниже, чем на парном глазу на 0,18 и 0,19 лог. ед. в обеих группах (p=0,02) (табл.).

На четвёртой минуте исследования ФСЧ в 1 группе была равна $(0,42 \pm 0,08)$ лог. ед., а во вто- 
рой - $(0,27 \pm 0,02)$ лог. ед. $(\mathrm{p}<0,05)$, также отмечалась тенденция к более низким значениям в сравнении с парным глазом.

На шестой минуте показатель ФСЧ составлял $(0,98 \pm 0,10)$ лог. ед. в первой группе и существенно ниже $(0,42 \pm 0,20)$ лог. ед. $(\mathrm{p}<0,05)-$ во второй. В первой группе показатели ФСЧ на больном и парном глазу не имели значимых отличий, во второй группе (без кортексина) - на 0,63 лог. ед. ниже $(\mathrm{p}<0,05)$. K окончанию семиминутной темновой адаптации

показатель ФСЧ на больном глазу в первой группе равнялся $(1,21 \pm 0,08)$ лог. ед., а во второй - значимо ниже - на $37 \%(0,76 \pm 0,15)(\mathrm{p}<0,05)$. В сравнении с парным глазом в первой группе отмечалась лишь тенденция к более высоким значениям на неоперированном глазу, во второй группе они были ниже на 0,47 лог. ед. $(\mathrm{p}<0,05)$.

Таким образом, в I группе больных, получавших кортексин, ФСЧ была значимо выше на 4, 6 и 7 минутах исследования, чем во второй группе.

Таблица 1

Показатели фотопической световой чувствительности у больных I и II групп (лог. ед.)

\begin{tabular}{|c|c|c|c|c|c|}
\hline \multirow{2}{*}{ ФСЧ (минуты) } & \multicolumn{2}{|c|}{ Групп I } & \multicolumn{2}{|c|}{ Групп ІІ } & \multirow{2}{*}{ Контроль } \\
\cline { 2 - 5 } & Оперированный глаз & Парный глаз & Оперированный глаз & Парный глаз & \\
\cline { 2 - 5 } & $\mathbf{M} \pm \mathbf{m}$ & $\mathbf{M} \pm \mathbf{m}$ & $\mathbf{M} \pm \mathbf{m}$ & $\mathbf{M} \pm \mathbf{m}$ & $0,21 \pm 0,06$ \\
\hline 1 & $-0,45 \pm 0,08$ & $-0,38 \pm 0,09$ & $-0,70 \pm 0,07$ & $-0,6 \pm 0,10$ & $0,73 \pm 0,13$ \\
\hline 2 & $0,06 \pm 0,08$ & $0,24 \pm 0,10$ & $0,01 \pm 0,17$ & $0,20 \pm 0,10$ & $1,18 \pm 0,12$ \\
\hline 4 & $0,42 \pm 0,09^{*}$ & $0,58 \pm 0,10$ & $0,27 \pm 0,02$ & $0,40 \pm 0,10$ & $1,52 \pm 0,10$ \\
\hline 6 & $0,98 \pm 0,10^{*}$ & $1,08 \pm 0,10$ & $0,42 \pm 0,20$ & $1,05 \pm 0,06$ & $1,74 \pm 0,08$ \\
\hline 7 & $1,21 \pm 0,08^{*}$ & $1,33 \pm 0,08$ & $0,76 \pm 0,15$ & $1,23 \pm 0,08$ & 1,08 \\
\hline
\end{tabular}

Примечание: * - уровень значимости различий между показателями ФСЧ на оперированных глаза в I и II группами р $<0,05$.

При сопоставлении с контрольной группой, которую составили пациенты с неосложненной миопией аналогичного возраста, снижение ФСЧ было выявлено на протяжении всего исследования: на первых минутах - до $91 \%$ в 1 группе и 98,6 \% - во второй; на 4 минуте - на $64 \%$ и $77 \%$, на 6 минуте на $35 \%$ и $72 \%$, на 7 минуте - на $30 \%$ и $56 \%$ в I и II группах соответственно $(\mathrm{p}<0,05)$.

Анализ результатов показателей фотопической световой чувствительности свидетельствует о резком снижении ее активности даже при анатомическом восстановлении структур глаза после оперативного вмешательства при такой тяжелой патологии как РОС, где локально нарушаются не только межнейрональные взаимодействия, но и выражено ишемическое состояние сетчатки. Снижение активности ФСЧ выявлено и на парном глазу (в среднем на $25 \%$ ), что, вероятно, можно объяснить несколькими факторами - окуло-окулярными взаимодействиями, хроническими ишемическими расстройствами и т.д.

Применение кортексина имело положительное влияние на ФСЧ, что объясняется его нейротропным влиянием на сетчатку.

Повышение световой чувствительности в результате применения кортексина описано в работах В. П. Еричева и соавт. 2005 г. [5], Л. А. Сухаревой (2010) [12, 13]. Так, по данным Л. А. Сухаревой, механизмы положительного влияния кортексина на ретинальную функцию при глаукомной оптической нейропатии связаны с улучшением активности фоторецепторов и биполярных клеток, межнейрональных взаимодействий на уровне внутреннего плексиформного слоя и глио- нейрональных взаимодействий в интерфейсе фоторецепторы/клетки Мюллера при наиболее выраженном эффекте в зоне в 5-6 градусов центральной сетчатки. Улучшение световой чувствительности по данным статической компьютерной периметрии отмечено автором в пределах центрального поля зрения.

Во временном аспекте по данным В. П. Еричева с соавт. [5] улучшение световой и контрастной чувствительности при начальной и развитой ПОУГ регистрируется лишь через три месяца после проведения курсового лечения, в работе Л. А. Сухаревой [13] отмечено влияние лечения на электрогенез сетчатки и световую чувствительность как непосредственно после лечения, так и спустя шесть месяцев.

Таким образом, применение кортексина приводит к повышению активности зрительного анализатора, а именно, основной его функции - световой чувствительности у пациентов с устойчивым прилеганием сетчатки после операции по поводу ее отслойки.

\section{ЛИТЕРАТУРА}

1. Анисимова Г. В. Применение пептидных биорегуляторов (ретиналамин, кортексин) в комплексном лечении хориоретинальных дистрофий / Г. В. Анисимова. Автореф. дис. ... канд. мед. наук. - М., 2002. - 29 с.

2. Бурчинский С. Г. Ноотропы - лекарства XXI века: новые возможности выбора / С. Г. Бурчинский // Аптека. - 2004. - № 34. - С. 6-11.

3. Бурчинский С. Г. Регуляторные нейропептиды новый этап развития проблемы нейропротекции / С. Г. Бурчинский // Судинні захворювання головного мозку. -2007 . - № 2. - С. 1-4. 
4. Герасимова М. М. Влияние Кортексина на терапию острого периода ишемического инсульта / М. М. Герасимова // Кортексин. Пятилетний опыт отечественной неврологии. - СПб: Наука, 2006. - С. 82-88.

5. Еричев В. П. Сравнительная оценка нейропротекторного действия пептидных биорегуляторов у пациентов с различными стадиями первичной открытоугольной глаукомы / В. П. Еричев, А. М. Шамшинова, Дж. Н. Ловпаче и др. // Глаукома. - 2005. - № 1. - С. 18-24.

6. Каменских Т. Г. Клинико-экспериментальное обоснование применения препарата «Кортексин» в лечении частичной атрофии зрительного нерва / Т. Г. Каменских, А. Н. Башкатов, В. В. Тучин, Э. А. Генина http:// www.rmj.ru/articles_5260.htm

7. Либман Е. С. Состояние и динамика слепоты и инвалидности вследствие патологии органа зрения в России / Е. С. Либман, Е. В. Шахова // Тезисы докладов VII Съезда офтальмологов России. - Москва, 16-20 мая 2000. - С.209-214.

8. Макаров П. Г. Организационные аспекты повышения эффективности лечения больных отслойкой сетчатой оболочки глаза / П. Г. Макаров, А. А. Пахабов, Т. Л. Манькова, Г. М. Сычев // Офтальмол. журн. 1989. - № 6. - С. 372-374.

9. Максимов И. Б. Способ лечения дистрофических заболеваний глаз / И. Б. Максимов, В. Х. Хавинсон, Л. К. Мошетова, Г. В. Анисимова // Патент Российской Федерации RU2195297. 2000.01.20
10. Меркулов И. И. Клиническая офтальмология / И. И. Меркулов. - М.: Медицина, 1964. - 348 с.

11. Новохатский А. С. Заболевания глаз при патологии вегетативной нервной системы / А. С. Новохатский, В. С. Пономарчук. - К.: Здоров я, 1988. -128 с.

12. Сухарева Л. А. Влияние препарата Кортексин на стабилизацию зрительных функций при первичной открытоугольной глаукоме с компенсированным внутриглазным давлением / Л. А. Сухарева, Н. В. Душин // Материалы XIV Российск. нац. конгресса «Человек и лекарство». - М., 2007. - С. 220.

13. Сухарева Л. А. Влияние нейропептидов на стабилизацию зрительных функций при глаукомной оптической нейропатии / Л. А. Сухарева. Автореф. дис. ... канд. мед. наук. - М., 2010. - 28 с.

14. Pastor J. C. // Surgical outcomes for primary rhegmatogenous retinal detachments in phakic and pseudophakic patients: the Retina 1 Project-report 2 / J. C. Pastor, I. Fernбndez, R.E. de la Rъa // Br. J. Ophthalmol. 2008. - V.92. - № 3. - P.378-382.

15. Hassan T. S. The effect of duration of macular detachment on results after the scleral buckle repair of primary, macula-off retinal detachments / T. S. Hassan, R. Sarrafizadeh, A. J. Ruby / Ophthalmology. - 2002. - V.109. - № 1. P.146-152.

Поступила 22.12.2011. Рецензент канд.мед.наук В. С. Дроженко

\title{
INFLUENCE OF CORTEXIN ON PHOTOPIC LIGHT SENSITIVITY IN PATIENTS WITH RHEGMATOGENIC RETINAL DETACHMENT
}

\author{
Ponomarchuk V. S., Khramenko N. I., Gaffari Sakhbi Ben Mohamed Monsef \\ Odessa, Ukraine
}

There were retrospectively studied the results of successful treatment of 18 patients (18 eyes) with the rhegmatogenic detachment of the retina (the first group) who obtained $10 \mathrm{mg}$ of cortexin in a 24 hour period (intramuscularly daily) for a period of 10 days after surgery in complex with the conventional therapy after the surgical treatment of patients, the controls (the second group) were composed of 25 people ( 25 eyes). The age of the patients of the basic and control groups ranged from 20 to 42 years, there was used sampling of patients with a maximally similar initial clinical state without the complications of surgical intervention (episcleral packing or complex intravitreal intervention (vitrectomy with gas tamponade) by a standard procedure).

The application of cortexin has led to the increase in the activity of the visual analyzer, namely, its basic function - light sensitivity in patients with the steady fitting of the retina after the operation for its detachment in the long-term period of follow-up (in 5-6 months). The indices of photopic light sensitivity on the sick eye in the first group (taking cortexin) had values of $1.21 \pm 0.08$ log.units, and in the second (the group of comparison) were significantly lower - by $37 \%-0.76 \pm 0.15(\mathrm{p}<0.05)$. 